\title{
UM OLHAR SOBRE A BIODIVERSIDADE: MAPEAMENTO DAS TESES -2016
}

Arlinda Cantero Dorsa ${ }^{1}$

Antonio Henrique Maia Lima

Nicolas Addor ${ }^{3}$

Thayliny Zardo 4

\section{INTRODUÇÃO}

Em 1992, a Convenção da Biodiversidade assinada no Rio de Janeiro por 156 Estados trazia expressa não só a conservação da biodiversidade como também a divisão equitativa e justa dos benefícios gerados com a utilização de recursos genéticos. Nela se chegou a uma definição bastante ampla e funcional de diversidade biológica ou biodiversidade, abrangendo-se três níveis: diversidade de espécies, diversidade genética e diversidade de ecossistemas.

A trajetória histórica do termo biodiversidade é recente e data de 1980 quando a palavra era considerada como sinônimo de riqueza de espécies, sendo que em 1982 passou a ser considerada diversidade genética e riqueza de espécies e finalmente em 1986 expandiu-se também para diversidade ecológica, sendo ainda neste ano substituída pela palavra biodiversidade, pois passou a ser "incorporada por ambientalistas, líderes políticos e cidadãos no mundo todo" (LEWINSOHN; PRADO, 2006).

A importância científica se relaciona com a discussão, nos meios acadêmicos, acerca importância da diversidade de tipos de vida na Terra. Essa é uma discussão realizada nas nervuras de diferentes áreas do conhecimento e por isso entendemos ser relevante para a

1 Profa Dra. PPGDL-Desenvolvimento Local - Universidade Católica Dom Bosco -MS (UCDB -MS)

2 Doutorando bolsista em Ciências Sociais pela Pontifícia Universidade Católica de São Paulo ( PUC/SP) ..

3 Mestrando bolsista em Direito Econômico e Desenvolvimento pela Pontifícia Universidade Católica do Paraná (PUC-PR).

4 Doutoranda bolsista do PPGDL- Desenvolvimento Local - Universidade Católica Dom Bosco (UCDB-MS) 
comunidade científica ter um panorama do que se produz em nível de pós-graduação strictu sensu no Brasil. Ao delinear o pano de fundo dessas produções, a partir de deduções propiciadas pela análise de resumo de teses, de palavras-chave e de nomes de programas de doutorado os trabalhos acadêmicos podem ser pesquisados e estudados por meio do chamado "estado da arte" ou "estado de conhecimento". Diante do exposto, é possível reconhecer que a produção de conhecimento da área de biodiversidade, tanto os avanços como também os limites, permitem a identificação de problemáticas, bem como a ampliação de conhecimentos em um dado campo. As revisões propiciam aos pesquisadores possibilidades de analisar e ou comparar pesquisas que tratam sobre temas semelhantes e perceberem a evolução das teorias apresentadas, observarem as tendências metodológicas utilizadas e aprofundarem conhecimentos sobre os aportes teóricos utilizados.

Assim, ao discutir e apontar indicações para a realização de estudos dessa natureza a partir do mapeamento de teses defendidas no ano de 2016 nas universidades brasileiras e pesquisadas no Portal de teses e dissertações da CAPES, tendo por descritor principal a palavra "biodiversidade" é o propósito científico em destaque. Portanto, o capítulo aborda inicialmente breves considerações metodológicas para, posteriormente, fazer uma pequena análise do "estado da arte" das produções científicas voltadas à biodiversidade.

\section{CONSIDERAÇÕES METODOLÓGICAS}

Denominadas como "de caráter bibliográfico", as pesquisas conhecidas como estado da arte ou estado de conhecimento têm em comum o caráter desafiador de se poder realizar um mapeamento que enseja discussão de determinada produção científico/ acadêmica em diferentes campos de conhecimento com o objetivo de tentar

[...] responder que aspectos e dimensões vêm sendo destacados e privilegiados em diferentes épocas e lugares, de que formas e em que condições têm sido produzidas certas dissertações de mestrado, teses de doutorado, publicações em periódicos e comunicações em anais de congressos e de 
seminários. Também são reconhecidas por realizarem uma metodologia de caráter inventariante e descritivo da produção acadêmica e científica sobre o tema que busca investigar, à luz de categorias e facetas que se caracterizam enquanto tais em cada trabalho e no conjunto deles, sob os quais o fenômeno passa a ser analisado (FERREIRA, 2002, p. 258).

Exatamente por realizarem uma metodologia de caráter inventariante, ainda segundo Ferreira (2002), ela possibilita as percepções de discursos que em um primeiro olhar nos apresenta como descontínuos ou contraditórios. O que move os pesquisadores interessados em realizar o mapeamento de produção de conhecimento é a sensação do não conhecimento acerca da totalidade de estudos e pesquisas e seu crescimento tanto quantitativo quanto qualitativo (idem). Nesse capítulo o que provoca os autores é a necessidade de uma reflexão desenvolvida na Pós-Graduação tendo como descritor a palavra "biodiversidade" e a sua inserção nos trabalhos de teses de doutorados no Brasil.

A busca dos pesquisadores a partir do estado da arte ou de conhecimento em sua opção metodológica parte do desafio de conhecer o que já é construído e produzido, objetivando dar conta de determinado saber assim como buscar o que ainda pode ser feito, pois, segundo Ferreira (2002), o estado da arte ou de conhecimento traz em comum o de se constituir pesquisas de levantamento e de avaliação do conhecimento sobre determinado tema ou ainda mais sinteticamente, como define Slongo (2004), são "pesquisas que estudam pesquisas".

Tais estudos, de natureza principalmente bibliográfica, visam responder "de que formas e em que condições têm sido produzidas certas dissertações de mestrado, teses de doutorado, publicações em periódicos e comunicações em anais de congressos e de seminários" (Ferreira, 2002, p. 258).

Há várias denominações e estudos realizados por diferentes autores para o levantamento voltado a revisões de literatura ou produção científica, uma delas são os "estudos de revisão", que são mapeamentos, um levantamento bibliográfico como 1 a etapa de um mapeamento que tem por finalidade levantar todas as referências encontradas sobre um determinado tema (CERVO; BERVIAN, 2002). Segundo os autores, essas referências são encontradas em 
diferentes formatos: livros, sites, revistas, vídeos, enfim todas as formas que possam possibilitar um primeiro contato com o objeto de estudo investigado.

Ampliam esta discussão Vosderau e Romanowski (2014), pois o material coletado pelo levantamento bibliográfico é organizado por procedência seja ele de fontes científicas: artigos, teses, dissertações ou fontes de divulgação de ideias (revistas, vídeos, sites) e permitem a construção de uma contextualização para o problema assim como a análise das possibilidades presentes na literatura para a concepção do referencial teórico de novas pesquisas.

O aprofundamento da análise pode se constituir no estado da arte ou de conhecimento por permitir estabelecer relações com produções anteriores, identificar temáticas recorrentes, apontar novas perspectivas de pesquisas assim como consolidar uma determinada área de conhecimento. Há, no entanto, a necessidade de os pesquisadores estabelecerem não só o campo e o tema a ser pesquisado como também, destaca Picheth (2007), estabelecerem uma determinada fonte de dados específicos como, por exemplo, uma base restrita por meio de uma revista ou uma base de dados mais amplos como teses ou dissertações.

O que não se pode perder de vista nos estudos do tipo estado da arte é que, antes de qualquer coisa, dois eixos estruturantes dão sustentação ao corpus teórico que se maneja, quais sejam: o aspecto quantitativo e o aspecto qualitativo. Numa frente de pesquisa se busca, como destaca Slongo (2004), o significativo crescimento numérico das produções e/ou a variação dessas produções num lapso específico de tempo sem que se considere, nessa vertente de atuação, a qualidade dessas produções. Em outra frente de pesquisa, por sua vez, se busca verificar as características dessa produção em detrimento de sua quantidade, logo, o que estará sob a análise, ainda para Slongo (2004) é a quantidade de enfoques e outras variáveis que o pesquisador queira analisar.

Como qualquer método de análise de dados e documentos a pesquisa sobre "estados de arte" possui limitações. Adverte Ferreira (2002) que existem alguns aspectos importantes que devem ser considerados e que demarcam os limites dos estudos desse tipo. A primeira limitação clarifica a ausência de um controle geral do pesquisador com relação ao seu objeto de investigação a partir da 
ênfase que a leitura do estado da arte proposta por ele reverbera em outras leituras, sendo assim haverá tantas histórias quantos leitores dispostos a lê-las: "[...] ele [o pesquisador] estará, quando muito, escrevendo uma das possíveis Histórias [...]" (FERREIRA, 2002, p. 269).

Para Silva e Carvalho (2014) a pesquisa do tipo "estado da arte" é um tanto quanto ritualística ou procedimental, segundo esses autores, antes de qualquer coisa é fundamental a realização de cortes, que servirão justamente para categorizar e definir de uma forma mais clara e compreensiva o corpo documental de análise.

Assim, o primeiro corte a ser feito é o corte de tempo, a partir dele se delimita o lapso temporal, a partir de um critério específico, cujos documentos oriundos serão dignos de análise.

O segundo corte fundamental é o corte de espaço, de onde sairão definidos, a partir de um critério específico também, como, por exemplo, a origem ou a localização, os documentos que, dentro do recorte de tempo serão analisados.

O terceiro corte é o corte temático, que "serve para definir e delimitar o que se busca mapear, possibilitando aos/às pesquisadores/as ou fazerem análises aprofundadas, ou realizarem um panorama amplo sobre determinados temas" (SILVA E CARVALHO, 2004, p. 349).

O penúltimo corte que talvez seja o mais importante de todos é a definição das fontes em que serão feitos os mapeamentos, os levantamentos, as análises, etc. Esse corte, salientam os autores, tem o condão de dar confiabilidade à pesquisa já que se espera rigor destas fontes no trato das publicações, trazendo um elemento ético fundamental.

O último recorte é $a$ forma de levantamento das referências, "pois delimita e norteia as buscas levando já a uma seleção e exclusão do que não será necessário" (idem). Geralmente essas procuras se dão por palavras chave dos trabalhos completos ou a partir dos títulos e resumos, o que, por diferentes razões pode deixar "escapar à filtragem" uma quantidade razoável de material que deixará de ser catalogado e analisado. (SILVA E CARVALHO, 2004).

Diante dessas reflexões, no presente estudo foi realizado um levantamento bibliométrico de teses referentes ao ano de 2016, e constantes no Banco de Teses e Dissertações da CAPES (Coordena- 
ção de Aperfeiçoamento de Pessoal de Nível Superior) e a partir das considerações de Slongo (2004) procuramos trazer à tona aspectos tanto quantitativos quanto qualitativos desse material.

\section{ASPECTOS QUANTITATIVOS}

Relembrando os dizeres de Slongo (2004) a pesquisa do tipo "estado da arte" busca em um primeiro momento um aparato genérico numérico das produções e a variação dessas produções num lapso específico de tempo. A partir dessas considerações dividiremos nosso estudo em duas etapas, sendo a primeira um demonstrativo geral das conotações quantitativas do material catalogado, filtrado e selecionado e na segunda adentraremos nos seus aspectos qualitativos.

Na primeira etapa foi realizada uma busca das teses no referido portal utilizando a seguinte palavra-chave: "biodiversidade". Com este critério foram resgatadas cerca de 160 teses, a partir da grande área: Multidisciplinar. As áreas de conhecimento apontaram com relação às respectivas teses: Biotecnologia -113 teses; Ciências Ambientais - 35 teses; Sociais e Humanas - 04 teses e Ensino - 01 tese.

Com a intenção de analisar em maiores detalhes as teses, foram selecionadas às referente as Ciências Ambientais (35 teses), assim como as informações sobre cada um dos trabalhos (universidade, programa de doutorado vinculado e respectiva avaliação, título, palavras-chave, linha(s) de pesquisa), conforme Figura 1.

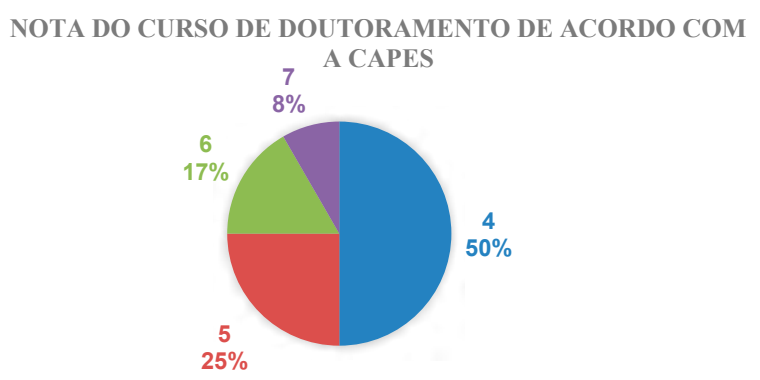

Figura 1. Proporção dos Programas quanto à avaliação no órgão competente Fonte: Construção dos autores. 
As teses mapeadas pertencem a 12 cursos de doutorado. Segundo a CAPES, o curso de doutorado avaliado com nota igual ou superior a 3 é "recomendado" ao reconhecimento ou renovação do conhecimento pelo Conselho Nacional de Educação. A nota é classificada entre 1 e 7. De acordo com a Figura 2, metade dos cursos possuem nota 4 , três com nota 5 , dois cursos avaliados com nota 6 e somente um curso avaliado com a nota máxima 7. Os cursos são:

- Doutorado em Ciência ambiental USP - nota 6

- Doutorado em Ciência ambiental UFPA - nota 4

- Doutorado em Ciência ambiental UFG - nota 5

- Doutorado em Ciências marinhas tropicais UFC - nota 4

- Doutorado em Meio ambiente UERJ - nota 4

- Doutorado em Ecologia aplicada USP-ESALQ - nota 7

- Doutorado em Desenvolvimento e meio ambiente UFPI-UFRN-FUFSE-UESC-UFPB/JP - nota 4

- Doutorado em meio ambiente e desenvolvimento regional Anhanguera - nota 4

- Doutorado em Ambiente e sociedade UNICAMP - nota 5

- Doutorado em Desenvolvimento sustentável UNB - nota 6

- Doutorado em Ciência, ambiente e sustentabilidade na Amazônia UFAM - nota 4

- Doutorado em Ciência do sistema terrestre INPE - nota 5

Neste momento, apresenta-se um gráfico referente às regiões de origem dos cursos de doutoramento.

\section{REGIÃO DOS CURSOS DE DOUTORAMENTO}

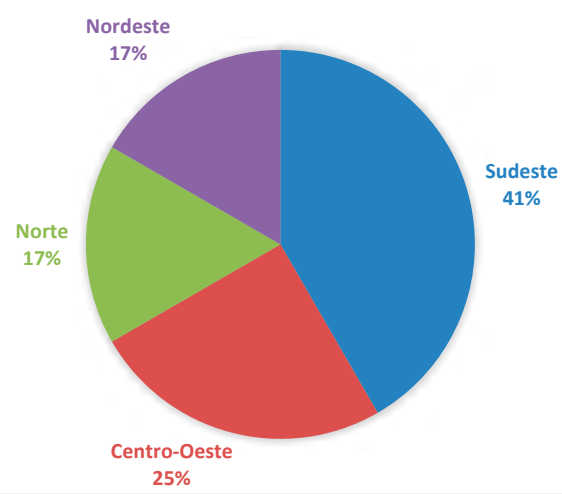

Figura 2: Distribuição dos Programas por Regiões

Fonte: Construção dos autores. 
Os cursos de doutoramento são provenientes de 4 das 5 regiões brasileiras, tendo a região Sudeste um número de 5 cursos ( 4 do estado de São Paulo e 1 do Rio de Janeiro), 3 cursos da região Centro-Oeste (1 de Mato Grosso do Sul, 1 do Distrito Federal e 1 do estado de Goiás), 2 da região norte (estados do Pará e Amazônia) e, por fim, 2 do Nordeste, sendo 1 do estado do Ceará e outro de proveniente de inúmeros estados: Sergipe, Bahia, Rio Grande do Norte, Piauí e Paraíba. A região Sul, entretanto, não possui nenhum doutorado de acordo com o mapeamento realizado (Figura 3).

\section{ORIGEM, POR REGIÃO, DAS TESES MAPEADAS}

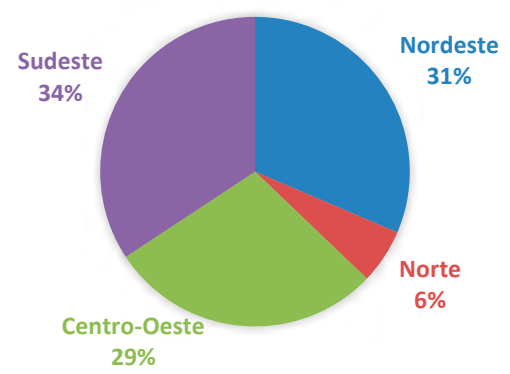

Figura 3: Origens das produções acadêmicas por regiões Fonte: Construção dos autores.

A região Sudeste, novamente, apresenta-se com o maior número de teses oriundas de sua região, com 12. Após, a região Nordeste com 11. Segue-se com Centro-Oeste, com 10 produções e, por fim, a região Norte com uma produção. Mais especificamente, tem-se as seguintes contribuições por universidades:

- Universidade Federal do Ceará - Cinco teses.

- Universidade de São Paulo - SP - Quatro teses.

- Universidade do Estado do Rio de Janeiro - Uma tese.

- Universidade Estadual de Santa Cruz - Três teses.

- ANHANGUERA - Sete teses.

- Universidade de São Paulo Piracicaba - Quatro teses.

- Universidade Estadual de Campinas - Uma tese.

- Universidade Federal do Piauí - Uma tese.

- Universidade Federal do Sergipe - Uma tese.

- Universidade Federal do Rio Grande do Norte-Uma tese. 
- Universidade Federal de Goiás - Uma tese.

- Universidade de Brasília - Uma tese.

- Instituto Nacional de Pesquisas Espaciais - Duas teses.

- Universidade Federal do Amazonas - Uma tese.

- Universidade Federal do Pará - Uma tese.

\section{ASPECTOS QUALITATIVOS}

Segundo Slongo (2004) é a quantidade de enfoques e outras variáveis que o pesquisador analisará na fase qualitativa de sua pesquisa de tipo "estado da arte". Seguindo os passos de Ferreira (2002) tentamos realizar um estudo qualitativo a partir dos resumos das teses encontradas. Para isso seguiremos o método desta autora empregado nos seus estudos a partir dos resumos da ANPED onde a autora buscou contar uma "história" da produção acadêmica na área da educação, no entanto, está muito longe de nossos objetivos a construção de uma "história" das produções sobre biodiversidade.

Como expresso no item 1 procuraremos enfatizar com um recorte transdisciplinar o que chamamos de "pano de fundo" das produções a nível de doutorado no ano de 2016 em torno da biodiversidade. Assim poderemos traçar, com sorte, uma espécie de "teia" em que será possível visualizar quais as temáticas em que estão se debruçando os pesquisadores da biodiversidade e como elas repercutem na academia.

Dos 12 programas de doutorado encontrados na varredura inicial já é possível identificar uma diagramação, ainda que superficial, das áreas do saber em que eles se inserem e como elas se correlacionam entre si. Apesar de serem as teses produzidas nosso objeto de análise, essa primeira diagramação servirá, pelo menos, para uma comparação a posteriori e uma análise da influência nas produções dos respectivos programas (Figura 4). Em um primeiro momento tivemos as seguintes palavras (algumas variantes) nos títulos dos programas: 


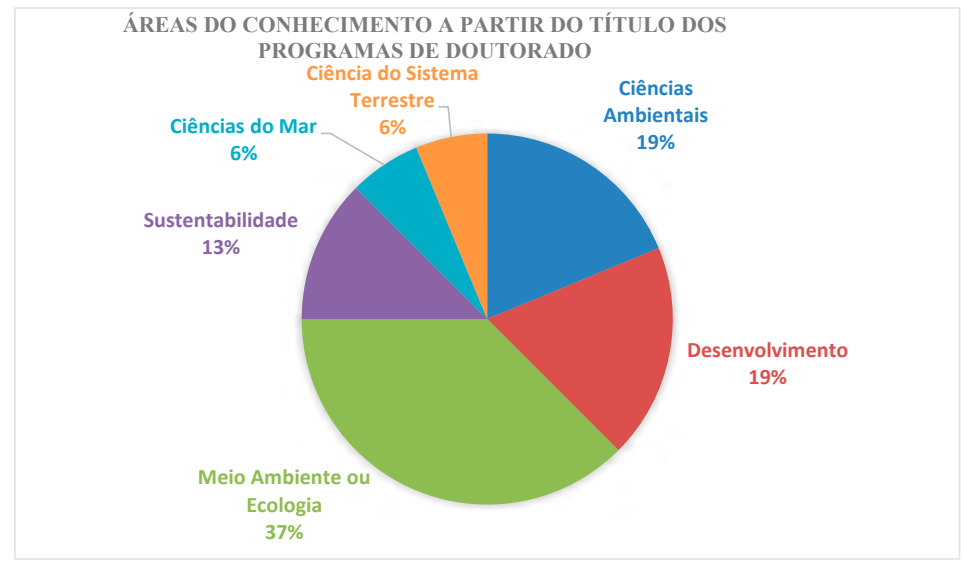

FIGURA 4: Áreas do conhecimento a partir do título dos programas de doutorado Fonte: Construção dos autores.

Quanto as teses mapeadas, analisaram-se as palavras-chave mais mencionadas pelos autores, estabelecendo, abaixo, as mais utilizadas (Tabela 1):

\begin{tabular}{ll}
\hline 2 Menções & $\begin{array}{l}\text { Políticas Públicas; Serviço Ecossistêmico; Desmatamento; Meio Ambiente; } \\
\text { Desenvolvimento Sustentável. }\end{array}$ \\
\hline 3 Menções & $\begin{array}{l}\text { Amazônia; Biodiversidade; Unidade de Conservação; Agricultura; } \\
\text { Degradação. }\end{array}$ \\
\hline 4 Menções & Sustentabilidade. \\
\hline
\end{tabular}

Tabela 1. Palavras-chave mencionadas nas Teses

Fonte: Construção dos autores.

Logo, baseando-se nas palavras-chaves mais mencionadas nas teses e nos títulos dos programas de doutorado, temos alguns enfoques que se destacam: primeiro, que é a questão da sustentabilidade e do desenvolvimento sustentável, ainda que o assunto central seja a biodiversidade, se apresentam como palavras mais recorrentes que esta última.

Nesse sentido é possível avaliar que a biodiversidade vem sendo, nas teses analisadas, tratada como um dos elementos primordiais para o desenvolvimento sustentável. A sustentabilidade da diversidade de espécies e de formas de vida é, portanto, o ponto chave das pesquisas realizadas nas teses abordadas, a partir de suas palavras-chaves, ressalte-se. Assim, a biodiversidade se apresenta 
menos importante enquanto um fim em si que enquanto meio ou elemento para o desenvolvimento sustentável ou para a sustentabilidade. Embora não tenhamos espaço para uma avaliação profunda, é salutar colocar em questão o discurso do desenvolvimento sustentável e a relevância que este vem ganhando no último meio século e que, nesse sentido, a biodiversidade é colocada como insumo para o processo de desenvolvimento, ainda que "sustentável" reproduzindo um modelo perpetrado pelo capitalismo desde a Revolução Industrial: grosso modo, por mais importante que seja a biodiversidade em si, ela é/passou a ser mais importante enquanto um instrumento do desenvolvimento ou uma engrenagem do mecanismo desenvolvimentista capitalista.

Utilizando da ferramenta wordcloud que projeta na forma de nuvem as palavras presentes nos resumos das teses em diferentes tamanhos, na medida da quantidade de vezes que aparecem, sendo que, quanto maior a palavra mais vezes ela apareceu no resumo, realizamos o seguinte exercício: compusemos com a ferramenta uma nuvem para cada tese de doutorado, e desta nuvem retiramos as três maiores palavras, reservando-as para ao final, compormos uma grande nuvem com as três palavras mais utilizadas em cada resumo para se ter um espectro global dos termos-chaves utilizados nas teses analisadas. Com esse método obtivemos a seguinte nuvem (Figura 5).

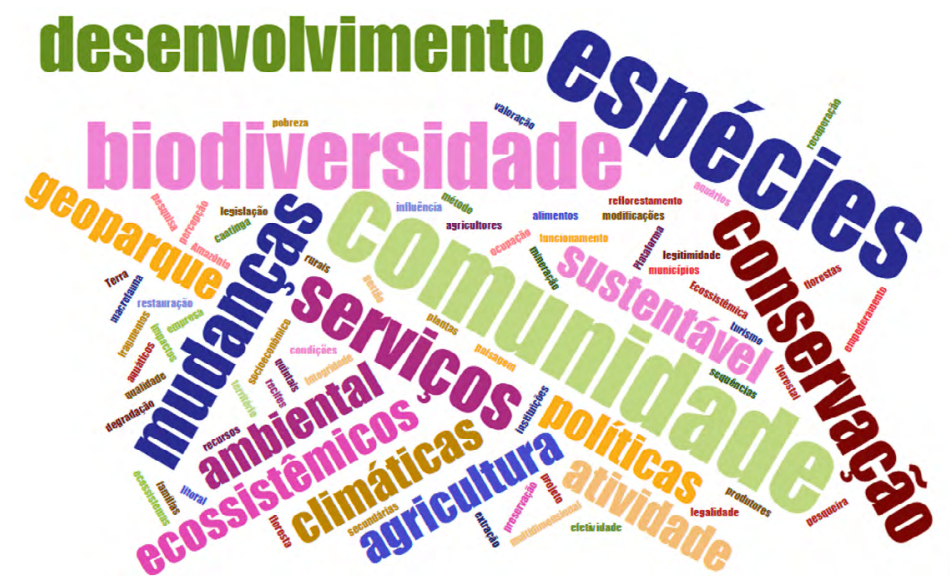

FIGURA 5: Nuvem de palavras-chave empregadas nos resumos das 35 teses analisadas

Fonte: Wordcloud. 
A partir da nuvem acima podemos visualizar que a palavra mais utilizada nos resumos das 35 teses analisadas foi "comunidade", seguida de "espécies", "biodiversidade" e "desenvolvimento", dentre outras. É possível deduzir que o termo comunidade aparece em primeiro lugar pelos seguintes fatores:

Estudos localizados: nesse caso os estudos ou pesquisas doutorais se concentram numa localidade específica, chamadas de comunidade, assim, o pressuposto da pesquisa empírica é uma análise da biodiversidade de uma determinada "comunidade".

Estudos de desenvolvimento: nessa segunda hipótese temos que associar a palavra comunidade com as demais palavras que aparecem em tamanho menor na nuvem, especialmente, "desenvolvimento", "sustentável", "sustentabilidade", "políticas", "agricultura", "atividade", etc. nessa segunda categoria, a palavra comunidade deriva da dinâmica dos estudos de desenvolvimento, especialmente, de desenvolvimento local, que se debruçam também sobre o estudo empírico de uma determinada localidade ou comunidade avaliando eventuais potencialidades ou políticas empregadas ou a serem empregadas ou desenvolvidas no âmbito da comunidade.

Comunidade biótica: nessa terceira categoria, o termo comunidade é empregado em algumas teses no sentido de comunidade biótica, ou seja, diz respeito ao conjunto de seres vivos de uma mesma espécie ou de espécies distintas (populações) que têm por habitat uma mesma área e que podem de alguma forma estabelecer relações entre si. Se associarmos o termo comunidade com outros termos apresentados nas nuvens, como "espécies", "ecossistêmicos", "conservação", "biodiversidade", teremos um forte indício de que os estudos de comunidade biótica buscam estabelecer parâmetros ou políticas de conservação da biodiversidade de determinados ecossistemas. Nesse sentido, ainda na nuvem é possível ler termos como "caatinga" e "geoparque" que indicam a conformidade geográfica em que as comunidades bióticas foram abordadas por algumas teses.

A segunda maior palavra na nuvem apresentada é "espécies". Uma vez que estamos realizando toda uma discussão em torno da palavra biodiversidade, é inescapável que a palavra "espécie" ou "espécies", seja uma das mais proeminentes. Como já dito os estu- 
dos de biodiversidade são indissociáveis do estudo de "espécies", de "comunidade" de "espécies", etc. Nesse sentido, com exceção de "desenvolvimento" todas as demais palavras das cinco mais citadas nos resumos dizem respeito aos estudos de biodiversidade em si. Esse elemento é importante para uma discussão refratária, ainda que breve, a partir das conclusões possibilitadas com a análise dos nomes dos programas de doutorado e das palavras-chave apresentadas nas próprias teses.

Uma vez que a catalogação das teses se faz em função das palavras-chave nas plataformas ou bibliotecas digitais, é possível deduzir, com base naquilo que já foi exposto, que há uma preocupação dos doutorandos (podendo ser também dos próprios programas de doutorado ou mesmo dos orientadores) em fazer com que haja uma consonância de suas respectivas pesquisas com o objetivo geral dos programas de pós-graduação strictu sensu e ou mesmo suas linhas de pesquisa. A partir das políticas nacionais de desenvolvimento científico e tecnológico empregadas desde, pelo menos, o governo Lula no Brasil, tem-se frisado de forma sistemática a questão da sustentabilidade e do desenvolvimento sustentável enquanto política de Estado e de governo.

Tal discurso é uma consequência sistêmica do discurso dominante no mundo e nas agências da Organização das Nações Unidas que fomentam o desenvolvimento, como por exemplo, a FAO e o PNUD. Assim, tem-se uma sistematizada gestação/modificação/ criação de programas de pós-graduação voltados para a satisfação desses ideais de "desenvolvimento sustentável", ainda que não seja esta a temática específica de muitas teses, dentre as analisadas.

Para maiores esclarecimentos a respeito das escolhas políticas leia-se o Livro Azul da 4a Conferência Nacional de Ciência e Tecnologia e Inovação para o Desenvolvimento Sustentável.

As palavras-chave vêm também para satisfazer esses ideais das políticas de Estado e de governo, quais sejam: fomentar ciência que potencialize o desenvolvimento sustentável. Esse efeito cascata: política de Estado, programas de pós-graduação, linhas de pesquisa, teses de doutorado, cria uma atmosfera de que toda a produção acadêmica na área da biodiversidade está voltada para a promoção da sustentabilidade e do desenvolvimento sustentável, ainda que, na prática, não esteja. 
O poder das palavras-chave na classificação, catalogação, etc. insere as teses na variável quantitativa da produção para o desenvolvimento sustentável, por mais que, qualitativamente não. Isso reverbera em índices que a depender do critério de análise melhoram a imagem do país no exterior conferindo a alcunha de um "país preocupado com a sustentabilidade".

É importante frisar, que em nenhum resumo se viu, pelo menos explicitamente, uma análise crítica ou um questionamento da noção de desenvolvimento sustentável, como se não houvesse qualquer alternativa a essa política global ou, problematizando mais ainda, como se outra política ou alternativa fosse à contramão dos interesses de Estado e/ou de governo e dos grandes representantes dessa lógica desenvolvimentista, em suma, do mercado capitalista global.

Ainda que assim o fosse, podemos afirmar que a impressão que se tem é que, para esses agentes é mais importante "parecer sustentável" que, de fato, "ser sustentável" ou em outro viés de análise, que há ou estaria havendo uma pressão, ainda que implícita, para que os estudos voltados para a biodiversidade se enquadrem numa gama de estudos que dizem respeito ou vão ao encontro à lógica do desenvolvimento sustentável, com vistas à ideologia dos órgãos de Estado e de governo, do mercado capitalista e consequentemente das agências de fomento da ciência e tecnologia, como se a biodiversidade fosse importante somente ou fosse mais importante quando espelha esses ideais e com isso gera algum tipo de lucro.

No Livro Azul (2010), a inovação e a sustentabilidade aparecem como "imperativos para o desenvolvimento brasileiro". Nesse documento a biodiversidade é tratada num capítulo à parte numa discussão dos prognósticos para o desenvolvimento brasileiro "sustentável". O título deste item específico é "Biodiversidade - conhecimento e conservação com agregação de valor" (p. 73). Nele aparecem estampadas as projeções da política de Estado e algumas recomendações para a biodiversidade dentro da lógica do desenvolvimento sustentável, que vêm sendo, em maior ou menor grau, reproduzidos, pelo menos, nas palavras-chaves de teses, nos nomes e nas linhas de pesquisa dos programas de pós-graduação na área de ciências ambientais. 
Avançar na pesquisa básica é essencial ao conhecimento, à conservação e ao uso sustentável da biodiversidade brasileira. Promover levantamentos taxonômicos, mapeamentos e inventários da biodiversidade; modernizar as coleções biológicas brasileiras e consolidar sistemas integrados de informações sobre biodiversidade são tarefas urgentes. Para tanto, é necessário atualizar o marco legal de acesso à biodiversidade. Hoje, as dificuldades legais impedem o trabalho dos pesquisadores e das instituições nacionais. A limitação no uso de material biológico, bem como a dificuldade de permuta de material genético têm retardado os projetos de pesquisa e acentuado a pirataria (O Livro Azul, 2010, p. 73).

Defrontando essas constatações com as diretrizes nacionais para a ciência e tecnologia e para o desenvolvimento sustentável somos obrigados a questionar: porque não se deu a devida importância à biodiversidade antes? Por que se esperou que os recursos se tornassem escassos e, portanto, raros, para que lhes fosse atribuído valor? Por que a pesquisa e a inovação nessa área tão importante no âmbito da pós-graduação não teve tamanho incentivo antes? Assim, a partir das respostas a tais questionamentos nos esquivaremos de ensaiar por não ser esta a proposta do capítulo, mas sim extrair dados qualitativos e quantitativos de um conjunto de teses de doutorado na área da biodiversidade, que, no entanto, de alguma forma, perpassam estes questionamentos.

\section{REFLEXÕES FINAIS AINDA QUE PARCIAIS}

O ponto crucial desses apontamentos é que a biodiversidade somente passa a ter a relevância que tem hoje quando dela passa a depender o desenvolvimento do sistema capitalista, dado que outrora essa área era objetivada e vista com verdadeiro desprezo, isto quando não se via política públicas voltadas, por exemplo, para a "modernização" (leia-se desmatamento para a urbanização ou para o agronegócio) de áreas cruciais como a Amazônia, o Cerrado e a Mata Atlântica.

O fomento à pesquisa nessas áreas estratégicas, na esfera do discurso e da destinação de recursos inclusive, se revela nessa fissura entre as palavras-chave e os resumos das teses, quanto à questão da biodiversidade. 
Assim, grosso modo, o que procuramos revelar é que a ideia de desenvolvimento sustentável se impregnou numa proporção tão elevada nos estudos voltados para a biodiversidade que, ainda que não seja este o objeto das pesquisas, ele aparece como palavra-chave diante das políticas de fomento e da relevância dada à sustentabilidade no último decênio enquanto política de Estado.

Essa atmosfera dá um novo rumo para a pesquisa na área e estabelece novas prioridades, jogando luzes em pontos específicos (e de interesse) e obscurecendo outros pontos, que, pelo menos por hora, não são de interesse, o que não significa que não sejam importantes. O alerta que essa dinâmica faz acender é que, a importância tardia dada a esses pontos implique, verdadeiramente, na impossibilidade de reversão de um estado de profunda degradação, isto é, que seja "tarde demais".

\section{REFERÊNCIAS}

BRASIL, Rep. Fed do. Livro Azul da 4ạ Conferência Nacional de Ciência e Tecnologia e Inovação para o Desenvolvimento Sustentável - Brasília: Ministério da Ciência e Tecnologia/ Centro de Gestão e Estudos Estratégicos, 2010.

CERVO, A. L.; BERVIAN, P. A. Metodologia científica. 5. ed. São Paulo: Prentice Hall, 2002.

FERREIRA, Norma S. A. As pesquisas denominadas "estado da arte". Educação \& Sociedade, ano XXIII, n. 79, Agosto/2002

LEWINSOHN, T. M. e PRADO, P. I. K. L.. Síntese do Conhecimento Atual da Biodiversidade Brasileira. In: LEWINSOHN, T. M. Avaliação do Conhecimento da Biodiversidade Brasileira. Ministério do Meio Ambiente-MMA, Brasília. 2006. Vol. 1.

NÓBREGA-THERRIEN, S.; THERRIEN, J. O estado da questão: sua compreensão na construção de trabalhos científicos: reflexões teórico-metodológicas. Estudos em Avaliação Educacional, v. 15, n. 30, p. 5-16, jul./dez. 2004.

PICHETH, F. M. PeArte: um ambiente colaborativo para a formação do pesquisador que atua no ensino superior por meio da participação em pesquisas do tipo estado da arte. 2007. 139 f. Dissertação (Mestrado em Educação) — Pontifícia Universidade Católica do Paraná, Curitiba, 2007. Disponível em: http://www.biblioteca.pucpr.br/ tede/tde busca/arquivo.php?codArquivo=828. Acesso em: 10 jul. 2017.

SILVA, F. J. C.; CARVALHO, M. E. P. O estado da arte das pesquisas educacionais sobre gênero e Educação infantil: uma introdução. Anais do 18 REDOR - UFRPE. Disponível em: http://www.ufpb.br/evento/lti/ocs/index.php/18redor/18redor/ paper/viewFile/2192/648 Acesso em: 01 ago. 2017. 
SLONGO, I. I. P. A produção acadêmica em ensino de biologia: um estudo a partir de teses e Dissertações. Centro de Ciências da Educação, UFSC, Florianópolis, 2004. (Tese de Doutorado).

VOSGERAU, D. S. R; ROMANOWSKI, J. P. Estudos de revisão: implicações conceituais e metodológicas. Rev. Diálogo Educ., Curitiba, v. 14, n. 41, p. 165-189, jan./ abr. 2014. 